\title{
ARTES DE GOVERNAR A INFÂNCIA: LIGUAGEM E NATURALIZAÇÃO DA CRIANÇA NA ABORDAGEM DE EDUCAÇÃO INFANTIL DA REGGIO EMÍLIA*
}

\author{
Maria Isabel Edelweiss Bujes** \\ Universidade Luterana do Brasil (ULBRA)
}

\begin{abstract}
RESUMO: Este estudo faz uma análise da abordagem da Reggio Emília para a Educação Infantil. Assumindo uma posição pósestruturalista de inspiração foucaultiana, descreve a proposta italiana e anatomiza seus discursos. A utilização das ferramentas teórico-metodológicas possibilita determinar um espaço analítico no qual os domínios da ética e da política se cruzam permanentemente - para entender como operam as modernas práticas de subjetivação, nessas experiências educativas destinadas a crianças de tenra idade. $\mathrm{O}$ exame breve e pontual da referida abordagem possibilita destacar vocabulários provenientes de campos claramente identificáveis para indicar suas articulações, filiações, compromissos. Pressupondo-se que é a linguagem que permite tornar determinada "porção da realidade" pensável, mostra-se como as palavras podem tornar inteligíveis as práticas sociais e expressar direções desejáveis para ali produzir intervenções.
\end{abstract}

PALAVRAS-CHAVE: Governamento da Infância; Reggio Emilia; Tecno-logias do Eu; Manuais para Professoras

\footnotetext{
A produção deste texto está associada à pesquisa "Infância e discursos: uma análise pós-estruturalista de manuais, projetos e propostas de formação docente", realizada pela autora no Programa de Pós-Graduação em Educação da Universidade Luterana do Brasil. Versão preliminar do mesmo encontra-se publicada sob o título "Artes de governar a infância: no cruzamento entre a ética e a política", nos Anais da $30^{a}$ Reunião Anual da Anped, realizada em Caxambu/MG em 2007.

** Professora do Programa de Pós-graduação em Educação e do Curso de Pedagogia da Universidade Luterana do Brasil e pesquisadora da infância.E-mail: mibujes@ulbra.br ou mibujes@terra.com.br
} 


\section{ARTS OF GOVERNING CHILDHOOD: LANGUAGE AND CHILD'S NATURALIZATION IN THE REGGIO EMILIA APPROACH}

ABSTRACT: The study explores the Reggio Emilia approach to Early Childhood Education. Drawing upon a post-structuralist, foucaultian inspired position, it describes that Italian experience and anatomizes its discourses. The use of theoretical and methodological tools make possible to determine an analytical space - in which ethical and political spaces are permanently crossing - to understand how modern practices of subjectification operate in these educational experiences addressed to very young children. The approach brief and punctual analysis makes possible to point out vocabularies from clearly identified fields in order to indicate its articulations, lineages, commitments. Assuming that language makes thinkable a determinate "part of reality", I stress how words could give intelligibility to social practices and show desirable directions to interventions.

KEYWORDS: Gender; Teachers' Work; Teachers' Union

A criança é feita de cem (...) Cem mundos para descobrir.

Cem mundos para inventar

Cem mundos para sonhar A criança tem cem linguagens

(E depois cem cem cem)

Mas roubaram-lhe noventa e nove. (Fragmento do poema de Loris Malaguzzi

"As cem linguagens da criança")

"É sempre um problema de linguagem que se encontra na origem e na constituição do mundo. (...) qualquer prática social não existe fora das palavras que se usam em cada época para a descrever."

$$
\text { (Ó, 2003, p. 9) }
$$

O espaço mais amplo em que esta produção se inscreve é aquele que trata de examinar como os discursos pedagógicos têm significado as crianças pequenas e que possibilidades eles nos abrem para compreender as direções que tomam as práticas educacionais voltadas para este segmento da população. O movimento massivo de expansão da educação institucionalizada para crianças de zero-seis anos de idade, atingindo hoje níveis impressionantes em todo o mundo ocidental, nos leva a inquirir como alguns conceitos vieram se impondo na definição do que seriam práticas desejáveis, qualificadas, bem-estruturadas para levar a cabo as experiências educativas com as crianças, nos espaços formalmente a isso destinados. 
Por outro lado, num âmbito mais restrito, interessam-me propostas concretas, formuladas por alguns autores coletivos ou sistemas de ensino, em que as finalidades do processo educativo, a concepção do sujeito da educação, a orientação epistemológica do processo curricular, a filiação teórica de seus pressupostos sobre o ensino e a aprendizagem? as ênfases que são imprimidas ao processo educacional? se delineiam de modo singular, passando a ser vistas como modelos para práticas educativas que se disseminam pelo mundo afora.

Examino aqui, especificamente, alguns textos sobre uma de tais experiências que se dedicam a encontrar "outros moldes", "novas perspectivas", "formas criativas" para levar a cabo iniciativas práticas para cumprir, junto com as famílias, essa responsabilidade social crucial que é a de introduzir os seres humanos, desde a mais tenra idade, no complexo mundo que os cerca. Refiro-me aqui à proposta de Educação Infantil gestada e desenvolvida na região italiana denominada de Reggio Emília. Como os seus iniciadores/mentores negam-se veementemente a utilizar a palavra "modelo", respeitemos sua vontade e seus argumentos, usando para tal projeto a denominação genérica de "abordagem".

Apresentando a abordagem de Educação Infantil da Reggio Emília, os organizadores do livro As cem linguagens da criança - dois professores estadunidenses e uma italiana - assim a situam inicialmente:

Reggio Emília é uma cidade de 130.000 habitantes na próspera região da Emilia Romagna, no nordeste da Itália. Seu sistema municipal de educação para a primeira infância tornou-se reconhecido e aclamado como um dos melhores sistemas de educação no mundo (Newsweek, 2 de dezembro de 1991). Atualmente, a cidade financia e opera 11 escolas pré-primárias para crianças de 3-6 anos, bem como 13 centros para crianças de 0-3 anos. Nos últimos 30 anos, o sistema criou um conjunto singular e inovador de suposições filosóficas, currículo e pedagogia, método de organização escolar e desenho de ambientes que, tomados como um todo unificado, chamamos de abordagem de Reggio Emília. Essa abordagem incentiva o desenvolvimento intelectual das crianças por meio de um foco sistemático sobre a representação simbólica. (EDWARDS; GANDINI; FORMAN, 1999, p. 21)

O material que documenta o trabalho desenvolvido pelo sistema de educação daquela região do norte da Itália, apresentado no livro que tem por título o mesmo de um poema de Loris Malaguzzi, o inspirador/mentor da experiência, serve de material empírico para a análise que proponho neste texto. O recorte aqui apresentado faz parte de uma investigação que tem se ocupado de examinar os discursos pedagógicos que dão sustentação às propostas de Educação Infantil presentes naquilo 
que qualifico como "manuais" envolvidos com a formação de professoras para esta etapa educacional.

Cabe, então, justificar o sentido em que utilizo o termo "manual" e também o interesse que me move, como pesquisadora, em escrutinar este tipo específico de material empírico. Entende-se aqui "manual" como aquele tipo de obra que apresenta noções essenciais sobre uma ciência, uma técnica (FERREIRA, 1986, p. 1084), uma perspectiva teórica ou uma experiência prática e cuja finalidade é oferecer orientações básicas, recursos para a execução de algo, servir de apoio tutorial para se empreender alguma ação; um compêndio que se propõe apresentar um resumo, em forma condensada, sobre determinado assunto. Para selecionar os manuais que examino, realizei um levantamento em bibliografias de disciplinas de cursos de Pedagogia voltados para formar docentes para a educação das crianças de zero a seis anos.

O projeto de pesquisa do qual este estudo faz parte vem tomando como objetos de exame formulações discursivas provenientes de três obras amplamente utilizadas atualmente em cursos de Pedagogia. Trata-se de: Qualidade em Educação Infantil (ZABALZA, 1999), Aprender e ensinar na educação infantil (BASSEDAS; HUGUET; SOLÉ, 1999) e As cem linguagens da criança (EDWARDS et al., 1999). As duas primeiras, por terem sido escritas na Espanha, guardam grande relação com a reforma curricular realizada naquele país nos anos 1980, capitaneada pelo mesmo consultor das reformas curriculares brasileiras do final da década $1990^{1}$, e a última tem sua fonte nas festejadas experiências italianas de educação infantil, realizadas na região da Reggio Emília, depois da II Guerra Mundial. Creio que essas credenciais têm explicado a difusão de tal literatura, o que, de certa forma, impulsionou também a minha escolha.

A pesquisa foi inicialmente conduzida com a intenção de mapear como se organizam e se expressam os discursos sobre a infância nos materiais associados à formação docente, nesses "manuais de formação de professoras para a educação infantil". Tais estudos se voltaram para examinar algumas feições dos discursos pedagógicos quando se referem aos sujeitos da educação - as crianças de forma especial (ainda que não se tenha deixado de analisar as práticas enunciativas que se centram nas professoras, nas mães e nos pais e em outras figuras de relevo no cenário institucional). Neste caso, no entanto, examinar um dos manuais selecionados busca um alvo mais circunscrito.

Como a abordagem da Reggio Emília propõe um formato peculiar para a Educação Infantil, que abrange tanto considerações sobre as 
finalidades da educação das crianças desde a mais tenra idade, em espaços sociais específicos criados para isso, quanto perspectivas mais instrumentais, associadas às práticas diárias levadas a efeito, parece-me que há aqui um campo fértil para examinar os enlaces entre os propósitos mais amplos da experiência e essas modalidades de práticas. Examinar como as formulações, numa visão macro, comprometidas com a defesa de uma visão histórica, de uma destinação social e cultural da criança contemporânea - para que as educamos, para que mundo, ... - , se articulam com o campo prático ou se desdobram de forma mais pragmática, de modo a tecer os elos que aproximam as práticas daqueles fins pretendidos.

O que pretendo, a partir da teorização que inspira este trabalho, é olhar tal abordagem numa perspectiva analítica, descrevendo-a e anatomizando seus discursos. Mas isso se faz aqui com interesse em mostrar como podemos utilizar as ferramentas foucaultianas para determinar um espaço analítico - no qual os domínios da ética e da política se cruzem permanentemente - para entendermos como operam as modernas práticas de subjetivação nessas experiências com crianças de tenra idade.

Ao dar crédito à avaliação de Gardner, para quem o

sistema de Reggio pode ser descrito sucintamente da seguinte maneira: ele é uma coleção de escolas para crianças pequenas, nas quais o potencial intelectual, emocional, social e moral de cada criança é cuidadosamente cultivado e orientado. (...) a comunidade de Reggio, mais do que a filosofia ou o método, é a conquista central de Malaguzzi. Em nenhum outro local do mundo existe tamanha relação harmoniosa e simbiótica entre a filosofia progressiva de uma escola e suas práticas. (GARDNER, 1999, p. X),

a pretensão da discussão aqui empreendida é mostrar os efeitos produtivos do poder. Como uma cultura pedagógica se organiza e se afirma para indicar as competências morais, intelectuais e de outras ordens, daquele que deve ser educado, e vincular tais propósitos a determinadas iniciativas práticas, um conjunto de experiências pedagógicas bem-delineadas e constantemente submetidas a rigoroso escrutínio para avaliar sua eficácia? Ou, dito de outro modo: como uma abordagem para a educação infantil, neste caso, propõe-se pensar e encontrar modos de agir e de intervir sobre atitudes, disposições e comportamentos dos alunos?

Tais questões se vinculam a um interesse em trazer para o centro da arena os modos como as crianças e jovens têm sido colocados como problemas de governo das populações. O encontro da governamentalidade com as tecnologias do eu - conceitos foucaultianos que remetem um ao outro e se esclarecem mutuamente - possibilitaram a geração de uma 
aparelhagem conceitual para tornar explícita tanto uma visão micro (o indivíduo no seu próprio universo) quanto macro (preocupação com o governo da população no seu conjunto) (Ó, 2003). São, portanto, dinâmicas voltadas para a individualização e a totalização - que, agindo em conjunto, num só processo, possibilitam que se administre a vida de cada um e de todos, num jogo estratégico que tem por finalidade conduzir seus modos de ser e existir no mundo.

\section{INFÂNCIA E GOVERNAMENTO: O ENLACE ENTRE A GOVERNAMENTALIDADE E AS TECNOLOGIAS DO EU}

Como, de certa forma, já veio sendo anunciado ao longo do texto, este trabalho dedica-se a tratar do tema do governamento da infância. Tal expressão, cunhada a partir de uma inspiração foucaultiana (ainda que outros autores tratem extensivamente do tema e possam também ser vislumbrados no traiçoeiro emaranhado da minha escrita), é aqui entendida como o modo pelo qual o poder se exerce para conduzir as condutas dos seres humanos. Portanto, a noção de governamento que desenvolverei está relacionada a formas de exercício do poder sobre os indivíduos. Na perspectiva em que se inscreve esta análise, governar é agir sobre o campo da conduta alheia (ou da própria conduta) e as ações de governamento não se constituem como um modo próprio de ação das estruturas políticas ou de gestão do Estado, unicamente; referem-se, igualmente, àquelas formas de agir que afetam a maneira como os indivíduos condurem a si mesmos. Assim, quando falamos das ações de governar, não estamos nos referindo apenas às práticas que advêm do moderno Estado de direito, mas de algo muito mais complexo, difuso, mas enredado e não tão facilmente identificável, pois proveniente de muitos lugares e estabelecendo curiosas alianças. Utilizamos o termo "governamento" para nomear uma ação sobre o campo eventual da conduta alheia, uma ação sobre ações presumidas, possíveis.

Ao utilizar o termo gouvernement, Michel Foucault toma-o em, no mínimo, duas acepções diferentes: para referir-se ao "governo", como uma "instituição do Estado", em seus diferentes âmbitos - o governo do município, do estado, do país -, uma instância central "que toma para si a caução da ação de governar” (VEIGA-NETO, 2002, p. 19); e como práticas múltiplas, como "ação ou ato de governar". Neste segundo sentido, tais ações extrapolam a instância administrativa, o âmbito de atuação dos aparelhos e dos agentes estatais. Para o filósofo francês, muitas pessoas podem governar: "o pai de família, o superior do convento, o pedagogo e o professor em relação à criança e ao discípulo" (FOUCAULT, 1993a, 
p. 280). Para ambas as acepções, vinha sendo empregada a palavra "governo", nas traduções para o português. Mais recentemente, Veiga-Neto (2002) sugeriu que se utilizasse o termo "governamento" quando estivéssemos nos referindo às ações ou ato de governar, para, quem sabe, diminuir a ambigüidade e distinguir a instituição ("o governo") das práticas ou táticas para exercer o poder (o governamento) ${ }^{2}$.

Ao desenvolver suas teorizações sobre o poder, Foucault nos aponta que, com a passagem de uma "arte de governo" para a instituição de uma Ciência Política, no século XVIII, as ações de governamento se disseminam; elas tomam conta do tecido social, deixam de ser privilégio do Estado, ainda que, ao serem distribuídas por toda a sociedade e ao ocuparem-se da vida das populações, elas articulem interesses de diversas ordens que envolvem as mais variadas instâncias do corpo social.

Feitos esses esclarecimentos, no sentido de dar sustentação à linha argumentativa que aqui desenvolvo, reafirmo, pois, que parto de uma concepção que entende as ações de formação humana como uma problemática de governamento, vendo-o como um domínio prático e técnico que torna possível a ação de uns sobre os outros. Ora, para que se exerçam as ações tendentes a dirigir a conduta, o arsenal foucaultiano nos fala em "artes de governamento": um modo mais ou menos racional, mais ou menos refletido de fazer as coisas (BURCHELL, 1996). Também um modo mais econômico, já que não apenas centrado numa instância central, O Governo, mas "distribuído microscopicamente pelo tecido social" (VEIGA-NETO, 2002, p. 21) e que busca atingir o máximo de resultados, com mínima aplicação do poder. Assim, o campo das estratégias para governar os seres humanos, apesar de interessar fundamentalmente ao Estado, se realiza a partir de múltiplos interesses, em muitos lugares distribuídos pela sociedade.

Isso nos leva, numa perspectiva mais geral, a formular questões tais como as que seguem: Como se forma, então, o sujeito moderno? Por meio de quais mecanismos ele se reconhece como determinado tipo de sujeito? De que modo funcionam as racionalidades, as técnicas, as práticas para formatar, em determinadas direções, esses sujeitos? Se estas são operações mais ou menos racionais, de que tipo de cálculos se valem? Estamos, portanto, no terreno dos processos de subjetivação: dos modos de conduzir o eu para que ele se ajuste às dinâmicas políticas de governamento e às formas de conhecimento científico.

O governamento, portanto, pode resultar tanto de uma ação tendente a conduzir a conduta alheia, quanto daquelas empreendidas por 
todos nós no sentido de conduzirmos nossas próprias condutas. Tais ações, de um sujeito sobre os outros ou sobre si mesmo, remetem à idéia de que o exercício do poder se dá pela utilização de determinadas tecnologias. Por esta razão, as tecnologias de governamento são aqui significadas, a partir de uma inspiração foucaultiana, como ações calculadas para agir sobre o conjunto da população, com a finalidade de potencializar a capacidade de alguns para agir sobre as condutas próprias e alheias - suas forças, suas atividades, as relações que os sujeitos constituem entre si.

Essa idéia de tecnologia se apresenta bem explícita na formulação de Nikolas Rose (1998, p. 40): "as tecnologias humanas envolvem a organização calculada de forças e capacidades humanas, juntamente com outras forças (naturais, biológicas, mecânicas) e artefatos (máquinas, armas) em redes operacionais de poder". Para o autor, as tecnologias humanas constituem-se em montagens híbridas em que se mesclam conhecimentos, instrumentos, pessoas, sistemas de julgamento, construções e espaços, que estão sustentados no nível programático por determinados pressupostos sobre os seres humanos (ROSE, 1996).

Michel Foucault chamou de "tecnologias do eu" as ações de alguém sobre si mesmo, quando se interroga sobre sua própria conduta e procura se transformar, modificar sua vida para que ela incorpore certos valores éticos e estéticos. As tecnologias do eu, portanto, podem ser vistas como "todo este conjunto de técnicas performativas de poder que incitam o sujeito a agir e a operar modificações sobre a sua alma e corpo, pensamento e conduta, vinculando-o a uma atividade de constante vigilância e adequação aos princípios morais em circulação na sua época" $(\mathrm{O}, 2003 \text {, p. 5) })^{3}$.

Ao entendermos a dimensão ética como este exercício constante do sujeito que age para conhecer-se e transformar-se, esta relação do ser consigo, pode-se entender melhor como as operações de poder permitem que a ética se torne inteligível como um domínio da prática. Portanto, analisar as tecnologias inventadas para conduzir a conduta tem por propósito tornar mais explícita a forma como elas são postas em funcionamento: identificando como incluem uma reflexão sobre modos de potencializar a ação dos indivíduos, para propor a intervenção, isto é, para estruturar o campo de ação próprio ou alheio. Como nos advertiu Nikolas Rose, é preciso tornar determinado domínio da realidade suscetível de apreciação e cálculo para, sobre ele, justificar uma intervenção. Isso torna possível dispor de meios para moldar, instrumentalizar, normalizar as maneiras como os sujeitos se conduzem. Ao se tratar de formas de go- 
vernamento, é sempre uma questão de linguagem que está em causa, pois é a linguagem que põe à nossa disposição os mecanismos que tornam o tecido social passível de intervenção.

Quando assumimos uma forma de compreensão do currículo que o associa às tecnologias de poder, torna-se possível examiná-lo na sua condição de discurso pedagógico: um discurso que organiza, articula, permite pôr em ação não apenas determinados modos de falar e de pensar, mas que se torna, no interior do aparato escolar, um operador de distribuições - de indivíduos, de acontecimentos, de atividades, de enunciados, no espaço e no tempo (PALAMIDESSI, 2001). O raciocínio precedente permite afirmar, pois, que o currículo se inscreve tanto na ordem do saber quanto do poder. Assim: "Pode-se dizer que o currículo é uma organização particular do conhecimento geradora de significados, de tal modo que não fazemos uma trajetória escolar sem sermos profundamente afetados pelas coisas que ali aprendemos e, no caso docente, também pelo que ali ensinamos" (BUJES, 2004, p. 3).

Por tudo isso, o currículo tem para os indivíduos um caráter ordenador e disciplinador, pois certas disposições, modos de pensar, modos de classificar e hierarquizar se impõem de maneira não-forçada e que se concretiza pela participação dos indivíduos em sistemas simbólicos por meio dos quais devem interpretar e organizar o mundo para nele atuar.

Assim, o exame dos textos que orientam determinadas experiências pedagógicas é de crucial importância se quisermos entender os meandros de tais experiências, os modos de olhar que põem em funcionamento, as formas de pensar que acabam por instituir, o aparato documental que sugerem compilar. Pois:

São os vocabulários comuns, as orientações teóricas, as posições normativas e as formas de explicação que ajudam a estabelecer as formas de coordenação e associação entre indivíduos, grupos e organizações. Constrói-se um aparato conceptual capaz (i) de circunscrever problemas sociais, indicando medidas para sua gestão eficaz e (ii) de identificar os problemas de foro interno dos indivíduos mas para os transformar em assuntos públicos. (Ó , 2003, p. 83)

No entanto, é preciso aqui fazer uma advertência. Embora as experiências pedagógicas, os currículos e a pedagogia estejam implicados em sistemas de regulação e as ações humanas estejam inexoravelmente submetidas a relações de poder, este nunca se realiza integralmente, sempre compete com outras forças que se lhe opõem, é sempre assimétrico, incompleto, sempre inacabado, sempre carregando consigo um ingrediente de fracasso. Mesmo que a sociedade moderna tenha realizado um 
custoso e contínuo investimento na escolarização, há um espaço à margem nunca atingido, nunca dando conta de uma parte residual do corpo social. Talvez seja por isso que a escola esteja sempre em busca de justificação, sempre inventando novos programas, novas formas de atuar, novas alianças, sempre convocando à participação. Mas essa discussão não cabe aqui, por agora.

$\mathrm{O}$ que interessa, na realização de análises como a que aqui empreendo, é mostrar os elos, os enlaces, os compromissos da abordagem que examino, por meio dos seus discursos pedagógicos, com a governamentalidade. Como, em domínios relativamente restritos, caso dos textos apresentados na obra $A$ s cem linguagens da criança, se expressam preocupações de caráter político, que podem ser vistas como articuladas às práticas microfísicas a serem postas em funcionamento (ou que já o foram, segundo os relatos de experiência contidos no manual)? Como se estabelecem conexões, articulações, pontos de contato entre essas práticas micropolíticas e o interesse mais geral do Estado? Como se exerce o poder político, nestes casos, relacionando o governo de cada um a um projeto mais amplo de governamento da população? Como se articulam o singular e o plural?

Em suas análises sobre o poder, Michel Foucault aponta para o fato de, já nos séculos XV e XVI, no Ocidente, a educação se organizar e se comprometer com um processo de reestruturação do poder moderno (CASTRO, 2006). A escolarização paulatina dos meninos dos estratos mais privilegiados da população e, depois, das meninas e dos menos privilegiados faz parte de um amplo projeto de disciplinarização da sociedade, que até hoje não deixou de existir. No entanto, o caráter falho de tal projeto, sua insuficiência para lidar com a crescente complexidade dos agrupamentos humanos e da vida social fizeram com que os Estados modernos que se instalaram a partir do século XVIII instituíssem o chamado modelo biopolítico. Isto é, passassem a se preocupar com a vida da população para garantir-lhe saúde, educação, bem-estar, segurança, fecundidade, etc. Somando-se à disciplinarização normalizante dos corpos, que se aplicou em gerar uma individualidade disciplinada, corpos dóceis e úteis, o domínio do poder se estende para as populações, no sentido de controlar este corpo múltiplo, de muitas cabeças, e de estabelecer uma série de regulações voltadas para o corpo-espécie. São os fenômenos coletivos que se tornam alvo do poder, entre eles o da educação institucionalizada.

O biopoder apóia-se necessariamente em saberes: estatísticos, demográficos, médicos, higienistas, etc. Mesmo quando governa condutas 
individuais, tem como alvo a população (VEIGA-NETO, 2006). Assim, podemos conceber a governamentalidade como uma arte que está associada à biopolítica das populações; ela se efetiva com a concorrência de agências e autoridades heterogêneas que empregam variadas técnicas e conhecimentos científicos com a finalidade de avaliar e melhorar a riqueza, a saúde, a educação, os costumes, os hábitos da população (Ó, 2003). É no âmbito dessa arte de governar que o Estado moderno passa a se valer de técnicas de notação, coleção, representação, acumulação, quantificação, sistematização e transporte de informação. É também na sua esteira que se reinventam novas modalidades de divisão do tempo e do espaço social. Portanto, a verdade do Estado passa a ser aquela produzida pela ciência. Daí a importância dos saberes científicos e de sua relação com o exercício do poder.

\section{UMA PERSPECTIVA PARA OLHAR}

Passo, a partir daqui, a examinar como os proponentes e analistas da abordagem da Reggio Emília utilizam-se de um regime de enunciação que lhes permite justificar as concepções e modos de levar a cabo a experiência, lembrando que "governar significa agir segundo uma determinada descrição”. Assim, o governamento implica a circulação de discursos científicos e morais que justificam seu modo de operar sobre os homens e as coisas. Isso só se tornou possível uma vez que a população passou a se constituir como objeto de conhecimento. Desse modo, as operações poder-saber não só se explicam como um dispositivo ágil para o governo da população, como se tornam também critérios valiosos para o aperfeiçoamento ético.

Ao justificar sua opção por dedicar-se à educação e cuidados das crianças pequenas, Loris Malaguzzi mostra o papel que o conflito mundial, do qual a Itália acabara de sair, tem na sua escolha

também a Segunda Guerra Mundial, ou qualquer guerra, em seu trágico absurdo, pode ter sido uma forma de recomeçar do zero, viver e trabalhar para o futuro. Este desejo atinge uma pessoa, quando a guerra finalmente termina e os símbolos da vida reaparecem com uma violência igual àquela do tempo da destruição. (MALAGUZZI, 1999, p. 66)

Enuncia-se aqui (se retoma e se reforça), claramente, a idéia moderna de que a educação tem um compromisso com o porvir. Nos processos de reformulação ou regeneração social, cabe à educação o imperativo ético de "reconduzir" aos seus devidos eixos o processo civilizatório, ainda que isso implique práticas diametralmente distintas daque- 
las que vinham sendo praticadas no momento da crise (da guerra, neste caso).

Essa preocupação com o futuro, portanto, no marco de um discurso que se enuncia comprometido não só com a modelização moral, mas também com interesses mais gerais, no plano estatal, ganha contornos próprios, por meio de algumas escolhas semânticas que cabem ser ressaltadas, a partir da extensa e exemplar citação que se segue:

A primeira filosofia aprendida (...), no rastro da guerra, foi dar um significado humano, digno e civil à existência, ser capaz de fazer escolhas com idéias e finalidades claras, e ansiar pelo futuro da humanidade (...) [Algo a que sempre tentamos permanecer fiéis] surgiu das solicitações feitas por mães e pais cujas vidas e preocupações focalizavam-se sobre seus filhos. Eles pediam nada menos que esta escola, que haviam construído com suas próprias mãos, fosse uma espécie diferente de escola, uma que pudesse educar suas crianças de um outro modo. Especialmente as mulheres expressavam este desejo. A equação era simples: se as crianças possuíam direitos legítimos, então elas deveriam ter oportunidades de desenvolver sua inteligência e de serem preparadas para o sucesso que não deveria e não poderia lhes escapar. Esses eram os pensamentos dos pais, expressando uma aspiração universal, uma declaração contra a traição do potencial das crianças, e um alerta de que elas, antes de tudo, precisavam ser levadas a sério e merecer nosso crédito. (MALAGUZZI, 1999, p. 67)

No fragmento "um significado humano, digno e civil" para a existência, chama a atenção o grifo do próprio autor à palavra "civil". A expressão remete diretamente à crítica ao monopólio da Igreja Católica sobre a educação pré-escolar e ao predomínio das soluções de tipo custodial, presentes nas modalidades então em curso, ao que parece, nem dignas, nem humanas, segundo a crítica de Malaguzzi. O que fica apontado é o desejo do novo, do diferente, daquilo a que crianças e famílias "tinham direito"; mas, sobretudo, o desejo de que um sistema estatal (municipal), além de conseguir afastar-se daquele modelo que tanto havia servido ao mesmo Estado em épocas precedentes, pudesse oferecer "oportunidades de desenvolver a inteligência [das crianças para que elas fossem] preparadas para o sucesso que não deveria e não poderia lhes escapar". No decorrer dos relatos da experiência, passa-se a entender que o que ali está em questão é muito mais do que o saber-as competências intelec-tuais do aluno - mas, essencialmente, o ser, isto é, o modelo de cidadão que importa construir. Como enfatiza Malaguzzi:

[A conversa sobre educação], que também é política deve abordar continuamente grandes mudanças sociais, transformações na economia, na ciência, na arte e nos relacionamentos e costumes humanos. Todas essas forças mais amplas influenciam o modo como os seres humanos - até mesmo as crianças pequenas - lêem e lidam com as realidades da vida (1999, p. 71). 
Também é preciso apontar para a relação entre alguns conceitos presentes nas formulações: desenvolvimento da inteligência, potencial das crianças e preparação para um sucesso inescapável. Neste ponto, cabe perguntar como se teria produzido a subjetividade dessas crianças? Como o modelo de criança, desenhado acima: capaz, inteligente, fadado ao sucesso - teria influenciado as várias autoridades (municipais, escolares, familiares) para que se construísse a abordagem pedagógica capaz de levar à sua efetivação? E aí talvez fosse oportuno citar as palavras de apresentação (que já apareceram parcialmente mais atrás) dos organizadores do livro sobre a abordagem de Educação Infantil que examino neste texto:

Nos últimos 30 anos, o sistema criou um conjunto singular e inovador de suposições filosóficas, currículo e pedagogia, método de organização escolar e desenho de ambientes que, tomados como um todo unificado, chamamos de abordagem de Reggio Emília. Essa abordagem incentiva o desenvolvimento intelectual das crianças por meio de um foco sistemático sobre representação simbólica. As crianças pequenas são encorajadas a explorar seu ambiente e a expressar a si mesmas através de todas as suas cem "linguagens" naturais ou modos de expressão, incluindo palavras, movimento, desenhos, pinturas, montagens, escultura, teatro de sombras, colagens, dramatizações e música. (EDWARDS; GANDINI; FORMAN, 1999, p. 21)

As suposições pedagógicas que orientam o movimento de "translação" - dos princípios mais gerais (suposições filosóficas, curriculares, pedagógicas) até as práticas preconizadas como adequadas para as crianças pequenas (expressão da capacidade adulta de colocar à sua disposição experiências congruentes com tais princípios) - se fundam em formulações que se sustentam em regimes de verdade histórica e socialmente constituídos. O Humanismo moderno deu origem ao ideal de um sujeito unificado e coerente que teve um papel fundamental para articular pressupostos sobre os seres humanos, vistos como possuindo características tanto morais quanto fisiológicas, biológicas ou psicológicas que seriam próprias da espécie, universalmente distribuídas. Tais representações, a crença na existência de tais características, todo esse aparato conceitual, foi imprescindível para articular as idéias de predizibilidade e regularidade dos processos pelos quais passariam os indivíduos na sua marcha em direção a um "desenvolvimento integral". Assim, os discursos que orientam a pedagogia moderna, bem como a abordagem que examino, não fogem a esta classificação e, nelas, os modos de atuar dos sujeitos envolvidos na relação pedagógica, bem como os fins a que tudo isso se destina, não passam de construtos culturais datados; essas idéias não têm o caráter universal que o Iluminismo inventou para elas, nem um sentido de liber- 
tação dos grilhões da dominação social, como anunciaram as "filosofias da consciência". Eles não passam de manifestações de uma vontade de verdade, estreitamente associadas a estruturas de poder e dominação. Como disse Foucault:

A verdade é deste mundo; ela é produzida nele graças a múltiplas coerções e nele produz efeitos regulamentados de poder. Cada sociedade tem seu regime de verdade, sua "política geral" de verdade: isto é, os tipos de discurso que ela acolhe e faz funcionar como verdadeiros; os mecanismos e as instâncias que permitem distinguir os enunciados verdadeiros dos falsos, a maneira como se sanciona uns e outros; as técnicas e os procedimentos que são valorizados para a obtenção da verdade; o estatuto daqueles que têm o encargo de dizer o que funciona como verdadeiro. (FOUCAULT, 1993b, p. 12).

Portanto, são regimes de enunciação que são colocados em ação para estabelecer o nexo entre as aspirações mais gerais das autoridades (aqui representadas pelos proponentes da abordagem - o sistema público de educação, seus experts ou educadores e as famílias) e as práticas cotidianas junto às crianças:

O enfoque oferece-nos novos meios de pensar sobre a natureza da criança como aprendiz, sobre o papel do professor, sobre a organização e o gerenciamento da escola, sobre o desenho e o uso dos ambientes físicos, e sobre planejamento de um currículo que guie experiências de descobertas conjuntas e solução de problemas de forma aberta. (EDWARDS; GANDINI; FORMAN, 1999, p. 23)

Cabe, então, discutir, na seqüência deste texto, como são formuladas e se entrecruzam as propostas de interação configuradas pelas práticas pedagógicas, com aqueles propósitos mais gerais da abordagem, examinadas sucintamente nas seções precedentes deste trabalho.

\section{MEMÓRIA E HISTÓRIA NA CONSTITUIC̣ÃO DAS SUBJETIVIDADES INFANTIS}

A ênfase operacional da proposta da Reggio coloca-se na exploração do ambiente e nas possibilidades de dinamização das "linguagens naturais" das crianças para representá-lo. Lilian Katz (1999), uma das analistas do projeto, afirma que a experiência italiana demonstra que as crianças envolvidas na experiência são capazes de utilizar inúmeros meios gráficos para comunicar as informações adquiridas e as idéias exploradas durante o trabalho com projetos. Esta seria uma das suas faces distintivas em relação a outras experiências com crianças menores de 6 anos: o desenvolvimento da capacidade expressiva; a confiança infantil em tal 
capacidade; a disposição para aprender; a possibilidade de opinarem, sugerirem, fazerem solicitações; a oportunidade de desfamiliarizarem o que lhes é familiar, por meio da imersão profunda em tópicos que parecem conhecidos. Tudo isso, a meu ver, é potencializado por um trabalho de documentação por parte dos professores e professoras e de especialistas do programa, que registram de muitos modos a experiência - filmes, gravações, registros escritos e fotográficos, etc. Esses registros não são, no entanto, de caráter burocrático, para mostrar, um dia, aquilo que foi feito, uma mera crônica dos acontecimentos:

As representações visuais visíveis não são apenas produtos decorativos para serem levados para a casa no final do dia, os quais provavelmente jamais serão olhados ou discutidos novamente; em Reggio Emília, elas são recursos para uma exploração adicional e para um maior aprofundamento do conhecimento sobre o tópico (KATZ, 1999, p. 43).

A produção das crianças é acompanhada, então, com propósitos muito imediatos de realização de um registro para se tornar a memória de um processo tanto individual quanto coletivo e de propiciar também o controle das produções infantis, como se pode verificar pelas palavras da analista referida mais acima:

Os desenhos significam relativamente pouco sem a documentação feita pelos professores daquilo que as crianças disseram sobre o que observaram e viveram. Gravados, os comentários e discussões das crianças ofereceram aos professores um conhecimento sobre seus níveis de entendimento e seus enganos de percepção sobre fenômenos cotidianos (KATZ, 1999, p. 39).

Assim, este empreendimento de documentação, como um dos aspectos característicos e originais do projeto em análise, está alicerçado em - e se faz com - propósitos bem-definidos:

Os educadores perceberam que documentar sistematicamente o processo e os resultados de seu trabalho com as crianças serviria sistematicamente a três funções cruciais: [a] Oferecer às crianças uma memória concreta e visível do que disseram e fizeram, a fim como um ponto de partida para os próximos passos na aprendizagem; [b] Oferecer aos educandos uma ferramenta para pesquisas e uma chave para melhoria e renovação contínuas; [c] e oferecer aos pais e ao público informações detalhadas sobre o que ocorre nas escolas, como um meio de obter suas reações e apoio. (EDWARDS; GANDINI; FORMAN, 1999, p. 25)

A constante reativação da memória, de reconstituição do vivido, o apelo para que cada criança se volte em direção àquilo que produziu, ao modo como se sentiu, aos sucessos ou dificuldades na execução de um 
projeto constitui uma estratégia para tornar cada uma consciente dos processos em que está envolvida, para dar-se conta dessa possibilidade de refletir sobre si mesma, de poder "pensar o seu pensamento".

Estamos naquele terreno que Michel Foucault chamou das "práticas da experiência de si" ou das "tecnologias do eu", daquelas experiências nas quais o indivíduo se volta para si mesmo, em que se reconhece como sujeito, em que atribui um sentido às próprias condutas e às alheias. Assim, a experiência de si resulta de "um complexo processo histórico de fabricação no qual se entrecruzam os discursos que definem a verdade do sujeito, as práticas que regulam seu comportamento e as formas de subjetividade nas quais se constitui historicamente como aquilo que pode e deve ser pensado" (LARROSA, 1994, p. 43). Trata-se, portanto, daquelas práticas em que é produzida ou transformada a experiência que as pessoas têm de si mesmas. "A experiência de si, historicamente constituída, é aquilo a respeito do qual o sujeito se oferece seu próprio ser quando se observa, se decifra, se interpreta, se descreve, se julga, se narra, se domina, quando faz determinadas coisas consigo mesmo, etc." (LARROSA, 1994, p. 43)

Ou como diz Jorge do Ó, as práticas da experiência de si abrangem:

todo este conjunto de técnicas performativas de poder que incitam o sujeito a agir e a operar modificações sobre a sua alma e corpo, pensamento e conduta, vinculando-o a uma atividade de constante vigilância e adequação aos princípios morais em circulação na sua época ( Ó, 2003, p. 5).

Nessa direção, é possível compreender como essas tecnologias das quais estamos falando colocam em xeque a idéia das condutas éticomorais como manifestações de um eu interior. Elas podem ser entendidas como práticas em "que se elabor[a] ou reelabor[a] alguma forma de relação reflexiva do 'educando' consigo mesmo” (LARROSA, 1994, p. 36). Para esse mesmo autor (ibidem, p. 45):

Toda cultura deve transmitir um certo repertório de modos de experiência de si, e todo novo membro de uma cultura deve aprender a ser pessoa em alguma das modalidades incluídas nesse repertório. [Portanto] em qualquer caso, é como se a educação, além de construir e transmitir uma experiência objetiva do mundo exterior, construísse e transmitisse também a experiência que as pessoas têm de si mesmas e dos outros como sujeitos.

Essas práticas incluem, então, técnicas ou mecanismos de autovigilância, de auto-avaliação, de autonarração (de confissão), que têm como efeitos a construção e a transformação da consciência de si. 
Portanto, as tecnologias do eu, como um conjunto de operações narrativas, são vivenciadas/aplicadas/constituídas na experiência social dos sujeitos. Mas tais vivências, que levam os seres humanos a se verem e a se praticarem como um $e$, a se pensarem como predispostos ou destinados a "uma realização plena" como sujeitos, "não surgem como alguns sugerem de algum desejo ontológico, mas são, antes, os resultados de uma certa história e de suas invenções” (Braidotti citado por ROSE, 1996a, p. 172).

No caso da experiência que examino, as práticas que constituem a experiência de si - na relação pedagógica -, com seus inegáveis efeitos na constituição das subjetividades infantis, funcionam pela interiorização das regras, dos critérios, das exigências tanto da vida coletiva quanto das formas de conduta individual desejáveis, por parte do sujeito da educação. Elas não nascem de uma disposição interior, mas são ativamente produzidas nas relações sociais. Como afirma Ó, não se trata de uma inculcação, mas de um quadro de ações, de

uma multiplicidade de jogos estratégicos e de situações relacionais em que cada membro da população escolar [é] convidado a constituir-se a si mesmo como indivíduo autônomo, racional e, uma vez já fora da escola, capaz de dar seu contributo particular para a integração moral de todo o tecido social" (Ó, 2003, p. 3).

Por tal razão, tomam-se precauções especiais e utilizam-se estratégias de constante reiteração, de auto-avaliação, de uma expressão individual (na forma confessional) da própria conduta, para que se reforce esse sentido de auto-reflexão e autojulgamento tão necessários a certa estabilização dos modos de conduzir-se considerados desejáveis:

As crianças pequenas não são encaminhadas correndo ou seqüencialmente apressadas de uma atividade para outra diferente, mas são encorajadas, ao invés disso, a repetir as experiências fundamentais, a observar, reobservar, a considerar e reconsiderar, a representar e novamente representar. (EDWARDS; GANDINI; FORMAN, 1999, p. 25)

Isso se faz, como está formulado claramente no texto que examino, para "reforçar o senso de identidade de cada criança, através de um reconhecimento que vem de companheiros e adultos, a tal ponto que cada uma sentirá um senso suficiente de conforto e autoconfiança na escola" (MALAGUZZI, 1999, p. 79), mas também com a finalidade de fazer as crianças descobrirem "como a comunicação melhora a autonomia do individuo e do grupo. $\mathrm{O}$ grupo forma uma entidade especial, ligada por debate e diálogo, que se baseia em seus próprios modos de pensar, de se comunicar e de agir" (ibidem). 
Ainda que no jogo dessas relações, no interior do grupo, o indivíduo fortaleça suas competências sociais, cognitivas, comunicacionais, como se discute acima, talvez seja bom lembrar que, ao se estabelecer um diálogo entre os participantes, este está inexoravelmente marcado por limites e por injunções situadas para além do espaço em que se dão tais interações. Assim, autonomia e comunicação são processos envolvidos em redes complexas de regulação. Os dispositivos que atingem as crianças e que entrecruzam o local com o global, ao promoverem a "interiorização" das formas adequadas de elas se relacionarem e de atuarem socialmente, concorrem simultaneamente para uma hibridação das condutas, em que autonomia e autocontrole passam a ser considerados marcas identitárias dessas "novas" crianças.

Outro aspecto a ser enfatizado é a possibilidade de as crianças se reconhecerem como produtoras de conhecimentos, de poderem retornar a eles quando isso se fizer necessário. Como diz Katz (1999, p. 41), "as experiências precoces (...) podem formar uma disposição permanente para buscar a compreensão em profundidade sobre tópicos que mereçam atenção".

Retornando às considerações sobre aquela que é a pedra de toque da abordagem, a centralização nas capacidades expressivas e representacionais das crianças - as suas cem linguagens - como focos da interação entre adultos e crianças, é interessante recorrer ao que é dito em outra passagem do livro:

As representações impressionantes que as crianças criam podem servir como base de hipóteses, discussões e argumentos, levando a observações adicionais e a representação de novas. Usando esta abordagem, podemos ver como a mente das crianças pode ser engajada de maneiras variadas na busca de um entendimento profundo do mundo familiar a sua volta. (ibidem, p. 43)

Fica aqui caracterizada a preocupação moderna com as capacidades e aptidões das crianças que são descritas exaustivamente: não apenas no sentido de desenvolver nelas uma concepção peculiar de sua "natureza humana", mas também de quais são as condutas esperadas de alguém que assume tal condição.

De outra parte, é possível destacar a pretensão de deduzir, pelas suas manifestações concretas, como funciona a mente das crianças. Tudo isso caracteriza como a Psicologia colonizou nossos modos de pensar, descrever e construir os modos de ser criança, estando de fato na base "de todas as técnicas e dispositivos relativos à identidade e à conduta [infantil]" (Ó, 2003, p. 9). 


\section{AS ARTIMANHAS DA LINGUAGEM \\ E A ABORDAGEM DA REGGIO EMÍLIA}

Em que pese o desejo expresso pelos proponentes e analistas do sistema da Reggio Emília de romper com a tradição, de mostrar uma vontade de "fazer diferente", a abordagem proposta não escapa de algumas metáforas fortemente incrustadas no campo teórico-prático da Pedagogia: a da "criança natural", das "linguagens naturais", da "criança como aprendiz", da riqueza da "experimentação". Tudo isso mostra que o sistema guardou algumas "conquistas" e descartou, por obsoletas, outras formas de significar as crianças, o processo pedagógico, as formas de interação e de intervenção. Não deixemos escapar que a referência de Malaguzzi a autores seminais do século XX - Dewey, Wallon, Claparède, Decroly, Vigotsky, Erikson, Piaget... - mostra a estreita vinculação da educação contemporânea com a marca Psi. São formas de conhecimento desse campo que produziram e continuam a produzir todo um aparato teórico para a avaliação, o cálculo e a intervenção educativa. Oferecem, assim, um arsenal conceitual para descrever, categorizar, classificar os seres humanos, desde a mais tenra idade, permitindo às autoridades públicas e privadas utilizarem-se de um regime de enunciação para justificar seu governamento dos homens e das coisas.

Por outro lado, também se dá especial atenção aos relacionamentos entre os atores envolvidos, mediados pelas produções das crianças, que são vistas como trazendo vários benefícios a ambas as partes. " $\mathrm{O}$ primeiro é que as crianças são engajadas em um trabalho excitante, que inclui tomar decisões sobre o que representar, como representar, como coordenar esforços e resolver visões conflitantes dos vários colaboradores de um projeto" (KATZ, 1999, p. 47). Neste caso, cabe apontar para o peso indubitável que é atribuído às decisões metodológicas, ao como levar a efeito as práticas que favoreçam aquilo que é entendido como o "germe da individualidade", que estaria presente no interior de cada criança. Ao educador cabe variar metodologias para atingir as inteligências individuais, favorecer as práticas de autonomia, de iniciativa pessoal de cada um. A marca socializadora do modelo de educação da Reggio Emília não escapa ao ideal moderno de ajustar as práticas educativas ao que foi tomado, neste trabalho, como processos de governamentalização das crianças. Trata-se, neste caso, de mostrar como se articulam interesses num plano macro com pontuais intervenções para que cada uma se reconheça como alvo de uma atenção educativa especial, levada a sério e, portanto, digna de crédito e de valor: 
As crianças sabem que os adultos se empenham em explicar, fotografar, anotar, transcrever fitas, exibir muito cuidadosamente e assim por diante. As crianças sentem que os adultos falam uns com os outros, trazem à atenção de seus pais e os apresentam para um fluxo constante de visitantes interessados. Portanto, elas sabem - talvez em um nível pré-consciente - que os adultos consideram seu trabalho e suas idéias muito seriamente. (KATZ, 1999, p. 48)

Estamos aqui nos deparando com uma autêntica forma de emprego de tecnologias para forjar, por meio do esforço educativo, um tipo ideal de sujeito. Ao discutir o sentido que imprime à palavra "tecnologias", Popkewitz esclarece que

este entendimento de tecnologia tem menos a ver com máquinas ou “equipamentos" e mais com o conjunto de práticas que inculcam hábitos virtuosos $\mathrm{e}$ autodisciplina que fazem com que o indivíduo se sinta empoderado, com voz ativa e auto-realizado através de uma educação adequada. (POPKEWITZ, 2006, p. 265)

Tanto a autodisciplina quanto a auto-satisfação com a realização das tarefas acadêmicas tornam-se explícitas para as crianças por meio das intervenções adultas que apontam constantemente sua importância. Isso dá a elas um sentido de adequação e ressalta "a confiança das crianças em seus próprios poderes intelectuais, [reforçando] sua disposição de continuar aprendendo" (KATZ, 1999, p. 38). Como disse Malaguzzi, (1999, p. 77): "Uma vez que as crianças sejam auxiliadas a perceber a si mesmas como autoras ou inventoras, uma vez que sejam ajudadas a descobrir o prazer da investigação, sua motivação e interesse explodem". O que está em jogo não é apenas oferecer mecanismos que tornem "espontâneas" essas "capacidades" de auto-interpretação dos sujeitos infantis, mas, antes de tudo, fornecer-lhes indicações do quanto eles são capazes, criativos, competentes.

$\mathrm{E}$ aqui talvez fosse bom referir novamente as palavras de Gardner para nos fazer entender por que o sistema da Reggio Emília vem sendo considerado como uma das mais bem-sucedidas experiências de Educação Infantil dos últimos anos: "Em nenhum outro local do mundo existe tamanha relação harmoniosa e simbiótica entre a filosofia progressiva de uma escola e suas práticas” (GARDNER, 1999, p. X).

Ainda que a forma de encerrar o parágrafo anterior possa parecer laudatória, gostaria de destacar que minha intenção como pesquisadora não foi fazer qualquer louvação à experiência que conheço apenas a partir do que dela se diz. Como analista que se vale de um exame documental - daquilo que os proponentes e avaliadores da abordagem apre- 
sentam, num livro dedicado a proclamar as suas virtudes -, pretendi apenas anatomizar alguns dos discursos que nos apresentam a abordagem. $\mathrm{O}$ fiz acreditando especialmente que as operações para governar não podem prescindir da escrita. Foi preciso colocar a experiência em palavras, descrevê-la, realizar uma série de operações intelectuais, para poder explicar e conformar os modos de ser e as práticas educativas voltadas para as crianças pequenas daquela região italiana.

Assim, memória e história não se encontram apenas articuladas na constituição de sujeitos particulares, as crianças envolvidas nas experiências educativas levadas a efeito, mas também na consolidação de um modelo educacional que pretende, como nenhum antes dele, esta "alquimia perfeita" entre a experiência pedagógica propriamente dita e um programa de implantação de reforma educativa com vocação salvadora de resgate das almas infantis.

Como espero ter demonstrado, ao longo do texto, as narrativas sobre a criança - um sujeito ativo, pensante, autoconfiante - que fazem parte da experiência que acabo de analisar nem o descrevem com justeza e, muito menos, constituem uma verdade sobre sua essência infantil e sua natureza legítima. De fato, configuram realidades inventadas, modos de dizer históricos, ficções postas a prova para dar conta de urgências sociais em um tempo em que se dissiparam todas as certezas. A abordagem da Reggio, como tantas outras, demonstra "o poder da linguagem que se ergueu à volta da criança” (Ó, 2006, p. 293). Em que pesem afirmações em contrário, a pedagogia ativa e científica revivificada construiu o modelo de criança que era preciso produzir, experiências concretas encarregaram-se de testá-lo, com maior ou menor sucesso.

\section{REFERÊNCIAS}

BASSEDAS, E; HUGUET, T; SOLÉ, I. Aprender e ensinar na educação infantil. Porto Alegre: Artmed, 1999.

BUJES, Maria Isabel E. Abrindo a pedagogia a outros olhares. In: ZORZO, Cacilda; SILVA, L. D. da; POLENZ, T. (Orgs.) Pedagogia em conexão. Canoas: Editora da ULBRA, 2004. p. 42-64.

CASTRO, Edgardo. Leituras da modernidade educativa. Disciplina, biopolítica, ética. In: GONDRA, J.; KOHAN, W. O. Foucault 80 anos. Belo Horizonte: Autêntica, 2006. p. 6378.

EDWARDS, C.; GANDINI, L.; FORMAN, G. As cem linguagens da criança. Porto Alegre: Artmed, 1999.

FERREIRA, Aurélio Buarque de Holanda. Novo dicionário da lingua portuguesa. Rio de Janeiro: Nova Fronteira, 1986. 
FOUCAULT, Michel. A governamentalidade. In: FOUCAULT, Michel. Microfísica do poder. Rio de Janeiro: Graal, 1993a. p. 277- 293.

FOUCAULT, Michel. Verdade e poder. In: FOUCAULT, Michel. Microfísica do poder. Rio de Janeiro: Graal, 1993b. p. 1-14.

FOUCAULT, Michel. O uso dos prazeres. In: FOUCAULT, Michel. História da sexualidade. v. 2. Rio de Janeiro: Graal, 1998.

GARDNER, H. Prefácio - Perspectivas complementares sobre Reggio Emilia. In: EDWARDS, C.; GANDINI, L.; FORMAN, G. As cem linguagens da criança. Porto Alegre: Artmed, 1999. p. IX-XII

GORDON, Colin. Governmental rationality: an introduction. In: BURCHELL, G.; GORDON, C.; MILLER, P. The Foucault effect-studies in governmentality. Chicago: The University of Chicago Press, 1991. p. 1-53.

KATZ, Lilian. O que podemos aprender com Reggio Emilia. In: EDWARDS, C.; GANDINI, L.; FORMAN, G. As cem linguagens da criança. Porto Alegre: Artmed, 1999. p. 3758.

LARROSA, Jorge. Tecnologias do eu e educação. In: Silva, T.T (Org.). O sujeito da educação. Petrópolis, RJ: Vozes, 1994.

MALAGUZZI, Loris. História, idéias e filosofia básica. In: EDWARDS, C.; GANDINI, L.; FORMAN, G. As cem linguagens da criança. Porto Alegre: Artmed, 1999. p. 59-104.

Ó, Jorge Ramos do. O governo de si mesmo: modernidade pedagógica e encenações disciplinares do aluno liceal (último quartel do século XIX - meados do século XX). Lisboa: Educa, 2003.

Ó, Jorge Ramos do. A criança transformada em aluno: a emergência da psicopedagogia moderna e os cenários de subjectivação dos escolares a partir do último quartel do século XIX. In SOMMER, L.H.; BUJES, M. Isabel (Orgs.). Educação e cultura contemporânea. Canoas: Editora da ULBRA, 2006. p. 281-304.

PALAMIDESSI, Mariano. El orden y detalle de las cosas enseñables. 2001. Tese (Doutorado em Educação). Programa de Pós-Graduação em Educação, Faculdade de Educação, Universidade Federal do Rio Grande do Sul, 2001.

POPKEWITZ, Thomas. Tecnologia como Prática Cultural: Morfologias de Governamento. In: SOMMER, L.H.; BUJES, M. Isabel (Orgs.). Educaşão e cultura contemporânea. Canoas: Editora da ULBRA, 2006.

ROSE, Nikolas. Inventing Our Selves: Psychology, Power and Personhood. Cambridge: Cambridge University Press, 1996.

ROSE, Nikolas. Governando a alma: a formação do eu privado. In: SILVA, T.T (Org.). Liberdades reguladas. Petrópolis, RJ: Vozes, 1998. p. 30-45.

ROSE, N. Como se deve fazer a história do Eu?

Educação e Realidade, Porto Alegre, v. 26, n. 1, p. 33-58, 2001.

VEIGA-NETO, Alfredo. Coisas de governo... In: RAGO, M.; ORLANDI, L.B.L.; VEIGA-NETO, A (Orgs.). Imagens de Foucault e Deleuze - ressonâncias nietzschianas. Rio de Janeiro: DP\&A, 2002.

VEIGA-NETO, Alfredo. Dominação, violência, poder e educação escolar em tempos de Império. In: RAGO, Margareth; VEIGA-NETO, Alfredo. (Org.). Figuras de Foucault. Belo Horizonte: Autêntica, 2006. p. 13-38.

ZABALZA, M. Qualidade em educaşão infantil. Porto Alegre: Artmed, 1999. 


\section{NOTAS}

${ }^{1}$ Ao me referir a reformas curriculares, falo especificamente dos Parâmetros Curriculares Nacionais e do Referencial Curricular Nacional para a Educação Infantil, publicados na década 1990, que tiveram como um dos seus principais consultores César Coll.

2 Para uma detalhada discussão sobre o tema, ver "Coisas de governo..." (VEIGANETO, 2002, p. 13-34).

${ }^{3}$ Talvez fosse bom assinalar aqui as distinções que se fazem, em termos foucaultianos, entre ética e moral. Comecemos com as palavras do filósofo: "Para ser dita 'moral' uma ação não deve se reduzir a um ato ou a uma série de atos conformes a uma regra, lei, mas constituição de si enquanto sujeito moral, na qual o indivíduo circunscreve a parte dele mesmo que constitui o objeto dessa prática moral, define sua posição em relação ao preceito que respeita, estabelece para si um certo modo de ser que valerá como realização moral dele mesmo; e, para tal, age sobre si mesmo, procura conhecer-se, controla-se, põe-se à prova, aperfeiçoa-se, transforma-se". (FOUCAULT, 1998, p. 28). Penso que as distinções que Foucault faz, ao referir-se à conformidade dos atos morais como regra, lei ou valor mas também como rapport a soi - uma relação do sujeito consigo mesmo - nos permitem mostrar como o sujeito pode transitar de atos morais, num sentido mais estrito de obediência a códigos, ao domínio da ética: "às forma de relação consigo, aos procedimentos e às técnicas pelas quais são elaboradas, aos exercícios pelos quais o sujeito se dá como objeto a conhecer, e às práticas que permitem transformar seu próprio modo de 'ser'" (ibidem, p.30).

Recebido: $21 / 03 / 2008$

Aprovado: 30/05/2008

Contato:

Universidade Luterana do Brasil Programa de Pós-Graduação em Educação Avenida Farroupilha, 8001

São José

CEP 92425-900

Canoas - RS

Brasil

E-mail: mibujes@ulbra.brou mibujes@terra.com.br 